\title{
An Innovative Approach to Adult Education in a Two-year BScN Program: Creating Partnerships in Learning
}

\author{
Baiba Zarins \\ Nipissing University, Baiba.Zarins@uhn.ca \\ Lorraine M. Carter Dr. \\ Nipissing University, Icarter0101@gmail.com \\ Tammie McParland \\ Nipissing University, tammiem@nipissingu.ca
}

Follow this and additional works at: https://qane-afi.casn.ca/journal

Part of the Educational Leadership Commons, Higher Education Commons, and the Nursing Administration Commons

\section{Recommended Citation}

Zarins, Baiba; Carter, Lorraine M. Dr.; and McParland, Tammie (2015) "An Innovative Approach to Adult Education in a Two-year BScN Program: Creating Partnerships in Learning," Quality Advancement in Nursing Education - Avancées en formation infirmière: Vol. 1: Iss. 2, Article 6.

DOI: https://doi.org/10.17483/2368-6669.1025

This Article is brought to you for free and open access by Quality Advancement in Nursing Education - Avancées en formation infirmière. It has been accepted for inclusion in Quality Advancement in Nursing Education - Avancées en formation infirmière by an authorized editor of Quality Advancement in Nursing Education - Avancées en formation infirmière. 


\section{Introduction}

Today Canadian universities are challenged to shift from more traditional teaching and learning models to more innovative approaches. They are likewise required to meet the increasingly specialized needs of students and faculty. In part, these expectations have increased due to a competitive university marketplace (Reeves \& Reeves, 2008; Ryan, Carlton \& Ali, 2004). In this competitive environment, there is increasing interest in educational opportunities that merge theory with practice and prepare graduates for employment in the health care milieu.

This paper describes the early development of the Scholar Practitioner Program, a twoyear, second degree undergraduate program which was formally launched in September 2011. The program is grounded in a unique learning model built on a partnership between a university in a northern Canadian city and leading academic health sciences centres located in a large urban environment. The program is unique in its adult learner orientation, pedagogical strategies that involve the use of narrative and significant independence by learners, and heavy emphasis on learning through practice. While various challenges had been anticipated, they have been greater than conceptualized and substantiate the claim that innovation stirs strong emotions (Ellis, 2005, p.13).

In particular, the paper describes the evolution of the program from conception to its current status. It focuses on the strengths, weaknesses, and opportunities of delivering a novel program for adult learners in which there is distance from the university, curricular issues, and approval requirements of an oversight body to meet. Recommendations for administrators and educators considering innovative university programs as an alternative to traditional understandings and systems are also provided.

\section{Review of Relevant Literature}

This literature review progresses from a limited consideration of the trend towards innovation in contemporary university education to specific attributes of nursing education in Canada at the present time. As such, the review provides background to the Scholar Practitioner Program, which is fully discussed in the subsequent section. The Scholar Practitioner Program, a two year compressed nursing program, distinguishes itself from other programs by its philosophical and pedagogical orientations, experiential focus, and commitment to ensuring that graduates are practice ready nurses and scholars who have prepared for their careers in some of Canada's leading health care settings.

\section{Innovation in Contemporary University Education: Trends and Attitudes}

It seems reasonable to suggest that innovation would be highly regarded by stakeholders in university education. Universities hold a particular responsibility for preparing graduates for a society that, today, is distinguished by change and innovation. The truth is that innovation in education is not always readily embraced (Authors, 2013; Authors, 2012).

One example of uneasiness in relation to educational innovation is e-learning. Today elearning includes face-to-face classrooms in which instructional technologies (e.g., learning management systems, video and web-conferencing, mobile devices, etc.) are used; blended and web-enhanced learning environments; and independently accessed fully online learning environments (Salyers, Carter, \& Barrett, 2010; Salyers, Carter, Barrett \& Williams, 2010). While the literature presents different views on the connection between technology use and how we learn (Bullen, 2011; Bullen, Morgan, \& Qayyum, 2011; Tapscott, 2008), today's students use technology more than any generation before them, and there is strong interest among many 
students in integrating technology with learning. Portable electronic devices and wireless technologies have evolved significantly over the past decade and created drastic changes in our lives (Beckmann, 2010; El-Hussein \& Cronje, 2010). As students engage in what Brocade (2011) has referred to as "e-living," it should come as no surprise that they might also be interested in elearning as part of their learning lives. Still, certain universities as well as individual professors hold different views about how learning should occur to the exclusion of e-based approaches.

In contrast with the rapid evolution of technologies is the reality that pedagogical thinking in universities often occurs slowly, despite the fact that not exploring new pedagogies involves some risk (Margaryan, Littlejohn \& Vojt, 2011; Parson, Reddy, Wood, \& Senior, 2009). As suggested in the above example, while some institutions have recognized the potential of elearning, others continue to champion face to face learning as preferable to e-learning (Authors, 2012).

Technology is not the only area in which some universities have been reticent to change. For example, a growing number of universities are now challenged to adopt programmatic models that do not follow the typical cycles and regulations of existing university systems as well as learning models grounded in experiential principles. The former causes disruption to systems that accommodate learners who typically attend three hours of classes per week per course within an established academic calendar. The latter challenges a long history in academe where teaching and learning is an interaction between the teacher and student carried out in a classroom setting.

\section{Recent Patterns in Nursing Education}

Within the university environment, nursing education has, by contrast, been an early adopter of alternate ways of learning. In Ontario, since the mid- to late-1990s, nursing education has witnessed growth in its use of computers and Internet-based technologies. This reality has led to diverse distance-based programs in nursing. Nursing education can claim leadership in university education in other ways as well: in particular, how nursing education programs blend theory-based learning with practice-based learning stands out. In all schools of nursing across Canada, nursing educators and administrators work to develop and deliver theoretical and clinical courses that enable competent and confident entry to practice nurses.

In 2013, practice-based learning, experiential learning, and work readiness emerged as specific interests of the Ontario Ministry of Colleges, Training, and Universities. In documents called Strategic Mandate Agreements (SMAs), Ontario colleges and universities discussed their plans and ideas for improving the undergraduate student experience, "[Of] all the ideas forwarded, the ubiquitous focus on experiential learning among universities (experiential learning has always been a central element of college programs) [emerged as] noteworthy" (Higher Education Quality Council of Ontario, 2013, p.10). While universities may not always be known for their emphases on experiential learning, university nursing programs are the exception.

Nursing schools at Ontario universities are also demonstrating leadership through the several two-year compressed nursing programs now available to students who have completed a first degree. These programs arose out the need for more nurses in Ontario and provide opportunities for first degree graduates to continue their studies in nursing. Such programs can be offered in two years because the students who take them have already completed degrees that meet elective requirements. At the same time, while innovative in purpose, these programs generally operate within the traditional curricular and administrative structures of the university. 
Typically, there is a carefully established series of courses that students must successfully complete and in which they experience largely traditional forms of learning.

Although recent trends in nursing education in universities do display innovation, there remains, at the time of writing, considerable opportunity for programs of study that use nonmainstream pedagogies and structures that may or may not follow standard university structures. In terms of alternate pedagogies, one such pedagogy is what the literature calls narrative inquiry. While a well-accepted means of learning in the arts and humanities, narrative has only recently found its way into health education and practice. It follows though that, when clinical practice is complemented by narrative competence, practitioners may be better equipped to recognize, absorb, synthesize, interpret, and be moved by stories of illness. Such competence requires improvement of the provider's capacity for attention, reflection, representation, and affiliation with patients and colleagues; it is "through the stories [of our patients that] we hear who we are" (Reichert, Solan, Timm, \& Kalishman, 2008). Increasingly, other health professionals are using narrative strategies to help people re-frame their lives, while many health researchers are using methods involving narrative (Clandinin, 2007; Morse \& Richards, 2002). Although the benefits of narrative pedagogies are evident in the literature, the "differentness" of narrative can be challenging for some to understand, particularly in nursing where issues of patient safety are critical.

Similarly, when programs of nursing education exist 'outside the structural box' that most universities use, there can be stressors. Champions of unique programs, therefore, need to find ways to fit into systems designed for other times and more traditional program models. University staff such as those who work in the Registrar's Office can be equally challenged to find ways to accommodate the timelines and credit values of novel programs. Finally, there are uncertainties for program accrediting bodies, which, in general, recognize assessment strategies based on traditional models of nursing education and historically recognized ways of learning.

The Scholar Practitioner Program which is the focus of this paper is an example of a nursing program that challenges the systems and thinking of both its university home and national accrediting body. The next section, in addition to providing insight into the nature of program and outlining its history, shares the principal challenges and opportunities of what it means to be a different kind of nursing program on several levels.

\section{An Innovative Program: The Scholar Practitioner Program}

\section{A Snapshot of the Scholar Practitioner Program}

The foregoing review of literature has progressed from the broader scene of university education to the more specific characteristics of nursing education in Canada. It has also prepared the reader for an up-close consideration of a unique undergraduate nursing program offered in Canada - the Scholar Practitioner Program (SPP). To the writers' knowledge, there is no other undergraduate program in Canada similar to the SPP.

The program began in September 2011 with a cohort of 32 students. Designed as a limited enrolment program with one intake per academic year, the program includes six sequential terms of study. It is also a collaborative undertaking between a small northern university and a number of large health care institutions in a large urban setting. Together, they have created a community of learning. The program's distinctness derives from its use of pedagogies emphasizing narrative, experiential learning, independence in learning, and one to one preceptoring with a registered nurse within point-of-care environments. The SPP graduate is 
an entry to practice nurse who is a strong clinician and who is distinctly cognizant of the lived experience or story of the patient. He or she is also a scholar and thinker who practices lifelong learning, bases care decisions on evidence, and participates in nursing as a scholarly profession. The students in the program are advantaged in their development as scholars since they study and work in some of Canada's leading health sciences centres. Thus, they experience learning, research, and scholarship from the beginning of their studies in centres where these elements are central to the patient care experience and central to the institutions' nursing values.

\section{The Evolution of the SPP}

The genesis of the SPP began with a conversation between two nurse leaders, one representing the lens of the university and the other representing the point-of-care environment. Drawing on their extensive experience in nursing education and practice, and their conviction that there was a need for an experientially grounded nursing program and innovative approaches to post-secondary learning, they initiated discussions to explore a new model of nursing education that would involve a pan-Canadian collaboration.

Due to logistical, licensing, and geographic challenges, the initial model was refined and became a geographically-based model involving the northern and southern areas of one province. The northern stakeholder, or partner, was a School of Nursing at a small university. The southern partners were leading academic health sciences centres in a large metropolitan city. The program was, like all nursing education programs in Canada, based on the standards of practice and approval requirements of provincial and national regulators. For this program, the competency framework was built on the entry to practice standards of the provincial regulatory body and standards of the Canadian Association of Schools of Nursing (CASN).

\section{More about the Partnership}

In order to launch the SPP, a partnership document was developed and signed by the stakeholders, with each stakeholder being an equal partner. Meetings occurred to flesh out the learning model and environment and to begin curricular work. All participants were encouraged to contribute to the creative design of the program and documentation required by the provincial ministry overseeing colleges and universities and the University's Senate. Memoranda of understanding were prepared, outlining infrastructure arrangements, the appointment of faculty from the health sciences centres as adjunct professors with the northern university, capacity for placement of students in clinical settings, and in-kind resources (library access, point-of-care preceptors, IT support, and access to the University's learning management system). A decision was made to use the term co-learners for students in the SPP. The term co-learners is reflective of the program's focus on the development of knowledge as an integrated, non-hierarchical, selfdirected experience but within a community of learning involving a smaller cohort of learners and faculty than most nursing programs have.

\section{How the Program Works}

The SPP is a full-time two-year $\mathrm{BScN}$ program to which any individual who has completed an undergraduate degree in any field of study can apply. Interested persons apply to the program through a provincial application process for intake into the annual cohort which begins in September. Students submit undergraduate transcripts and request matching with one of the urban health centres as a base organization of clinical study. Supplemental application documents include an admissions essay and letter of reference. To ensure a strong understanding of fundamental concepts in health care, university-level knowledge of anatomy, physiology, and basic psychology are program pre-requisites. 
Qualifying applicants are invited to an admissions interview to assess the candidate's fit and understanding of the program's delivery methods, pattern of progression, expectations, and other benchmarks of success. In addition, the interview is a means of assessing that the applicant fully understands program expectations, including the principles of adult learning and independent learning. All qualifying candidates are interviewed before final decisions are made about offers of admission. A key area in which suitability is assessed pertains to the pedagogical principles and practices used in the program, namely, narrative inquiry and cognitive apprenticeship. Narrative inquiry pedagogy focuses on the processes of teaching; interpreting; thinking critically; and analyzing concepts, ideas, and situations. This particular approach to teaching and learning, in contrast with other approaches that may tend to be hierarchical in nature, fosters partnerships in learning (Connelly \& Clandinin, 1990, 1994). It is also suited for meeting the demands of today's changing healthcare environment (Eggertson, 2013; Higher Education Quality Council of Ontario, 2013; Ministry of Training Colleges and Universities, 2013). As a method of knowledge creation, cognitive apprenticeship explores diverse means of knowledge translation and uptake within health care and the intersections within the preceptorlearner-patient/client-faculty interface (Stalmeijer, Dolmans, Wolfhagan, \& Scherpbier, 2009).

Each semester is divided into three phases or courses called Inquiry, Transformative Practicum, and Reflection. In each phase, the learning strategies of narrative inquiry and cognitive apprenticeship are used. These strategies emphasize collaborations between the teacher and learner in order to understand experiences (Brown, Kirkpatrick, Mangum, \& Avery, 2008). During each three week Inquiry phase, the adjunct faculty lead introductory theme-based discussions. The ideas raised in these preliminary sessions are followed by richer discussions and research work by the co-learners. Group sessions include narrative accounts, case studies, formal assignments, personal learning events, and group presentations that facilitate knowledge exchange and interactive learning. Subject matter experts and guest lecturers from the University and point-of-care environments are invited to facilitate conceptual sessions. The learning involves research, issues of clinical competency, and leadership narratives that strengthen the 'academic to practice bridge' in preparation for the students' clinical practicums.

This intersection among the learner, the practitioner, and the environment is further actualized within the Transformative Practicum phase, when learners follow the schedules of their preceptors. At this point, learners begin to develop learning plans that document how they plan to achieve their semester-specific objectives. Students are expected to identify items of work or evidence that will indicate that these goals have been met.

Clinical practicums are described as transformative experiences that provide in excess of 200 hours in the first five semesters, and 300 hours in the final semester of the program. In total, co-learners are immersed in the partnering health care settings for more than 1,300 point-of-care hours during the program. This model provides tremendous opportunity for students to work and learn in a variety of health care settings; acquire hands-on practical experience; and manage their own learning while interacting with nursing academics, researchers, and other healthcare team members. Interprofessional collaboration and education are expected, as practice environments offer realistic and current opportunities to apply academic knowledge.

Of particular significance is the one-to-one preceptorship that each co-learner experiences during the clinical placements; this approach is reflective of the cognitive apprenticeship model. Preceptors who are registered nurses in point-of-care learning environments facilitate cognitive and professional growth by engaging in meaningful conversations and role modelling with the 
learners. The learners share their individualized learning plans with their preceptors for feedback and understanding of their goals for the practicum. This approach immerses the co-learner in the role of the nurse on a unit and in relation to a health care provision experience. The preceptor's ability to connect with the learner is central in the learning environment. By using the strategies of narrative inquiry, the preceptor and learner form a partnership through which they share and interpret experiences (Brown et al., 2008). A sense of trust between the preceptor and learner is essential if the learner is to explore and share ideas, reflect on personal actions, analyze clinical situations, and evaluate outcomes. The preceptor's understanding of the role and expectations is enhanced by in-depth orientations to the program by the adjunct faculty and professional development opportunities offered during the semester. The latter is important given the differentness of the program, including the preceptor-learner-faculty triad. Being paired with a preceptor and working the preceptor's schedule help the student to assume membership on the health care team in a non-hierarchical way, while the student is supported by the faculty member dedicated to the program. Discussions involving the preceptor, faculty, and learner enable achievement of learning plan objectives and feedback on learner progress. The creation and submission of learning portfolios provide evidence of achievement at many levels. Portfolio artefacts include evidence-informed narratives, aesthetic interpretations of experiences, videos, blogs, course work completed through independent study, and evidence of participation in professional development opportunities.

Learners also share their reflections about their practicum experiences during scheduled weekly sessions facilitated by the faculty. Consistency of faculty presence during the semester provides supportive modelling. The weekly sessions include opportunities to share clinical experiences, engage in collaborative learning with peers, and discuss assignments.

In the last phase of each semester, the cohort is brought together to discuss learning achieved over the semester. Benchmark evaluations including written exams, practical assessments based on simulated situations, and quizzes ensure that students are meeting formative milestones. Given the advent of e-learning technologies, most evaluation activities occur electronically, with students using their laptops and iPads.

In the SPP, achievement of course objectives involves independent as well as collaborative learning with other co-learners and the adjunct professors. These strategies are supported and used by faculty from the University and expert clinicians from the healthcare environments. Courses and placements are facilitated in the urban setting, although some students elect to explore consolidation placements outside of the city for specific semesters. This decision is generally made to follow specific interests of the co-learner and/or in anticipation of a possible nursing position in the alternate community after graduation.

\section{Where the Program Stands Today}

Each new cohort of students has contributed to the evolution of the program, enhancement of relationships among program stakeholders, and expansion of programmatic boundaries. The inaugural cohort graduated in Fall 2013. These graduates were not only nurses but also generators of new ideas, innovative and independent thinkers, and practitioners of

narrative in the health context. While all graduates of undergraduate nursing programs in Canada must meet the same standards for licensure, SPP graduates experience a particular advantage in relation to their evolution as scholars and personally motivated learners. This advantage stems from their immersion in point-of-care settings in some of Canada's most progressive and research-intensive health organizations. The graduates' progression to licensing and practice has 
meant an important contribution to meeting the demands of patients and families in contemporary society.

Graduation numbers, employment data, and student success on the Canadian Registered Nurses Exams (CRNEs) underscore the strength of the program. For the first cohort of students, a final success rate of $77 \%$ was reported (College of Nurses of Ontario, 2013); for a small first cohort, this value compares very favorably with those generated by students from much larger and more established nursing programs. More than $90 \%$ of graduates from the first cohort secured employment in organizations and areas of personal choice. The subsequent cohort experienced an $85 \%$ success rate in relation to licensure on the CRNE/National Council Licensure Examination (NCLEX) as well as a 92\% employment rate (College of Nurses of Ontario, 2014).

As the program evolves, it will be important to continue to support co-learners for entry into the nursing profession as practice ready scholars with an active voice in health care. The goal is that they will successfully contribute to the health and well-being of individuals, families, communities, and populations through evidence-based practice. Sustained interest in the program and valid and reliable evaluation metrics will further position this program as an option for adult learners wishing to pursue nursing after completion of a first or subsequent degree.

\section{Challenges and Opportunities}

\section{A Remote Campus}

Geography has played a large role in this program. In essence, this is an urban-based satellite program with the "parent" university located many kilometers away. This variable has been an opportunity and challenge for the program. While today's advanced communication technologies, including teleconferencing, videoconferencing, web conferencing, and other multimedia platforms, can support structured and informal relationships, geographic distance between the campuses can lead to a sense of detachment and lack of identity for students and faculty involved with the program. At the same time, through the noted technologies, increasing efforts by faculty and administrators from the University to visit the campus in the city, and the participation of SPP faculty in School of Nursing meetings, these issues are lessening. As well, over time, greater awareness has developed within the University of the needs of students studying at the distance from the main campus. Based on this awareness, services and activities that reach out to students in the SPP have increased. They include, but are not limited to, the supports of the student life centre, accessibility services, the University's common book program, and the University's undergraduate research conference.

SPP students have questioned their tuition costs, as they include on-campus services that are either inaccessible or severely limited to them as distance learners. This reality has mobilized the students to engage in dialogue with University administration. Students have displayed courageous leadership in representing the needs of off-campus students. In addition to the benefit of learning to mobilize and express voice, the students gain experience from their extensive exposure to and immersion in point-of-care environments. The most significant benefit for SPP graduates is the availability of immediate employment opportunities upon successful licensure.

While program specifics were developed, implemented, and refined by the adjunct professor faculty, the overall shape of the program and learning outcomes were developed in collaboration with School of Nursing faculty. The adjunct professor faculty members are responsible for co-learner progression in the program. Given this responsibility, the adjunct 
professor faculty balance dual roles: their work with the SPP and their obligations to their hospital or community agency employers. Overall, while this model facilitates student learning within experientially rich learning environments, the attentive dedication of the adjunct professors faculty in facilitating this environment is high. This responsive dedication was particularly commendable during the early years, when intensive refinement of the program and its infrastructure were required for accreditation purposes.

\section{A Different Approach to Curriculum}

Within the program, curriculum is defined as transactions and interactions that take place between co-learners and their teachers and among co-learners. The primary intent is that learning will take place through these transactions and interactions (Bevis \& Watson, 1989, p. 72). Curriculum-making is an 'account of teachers' and students' lives together in schools and classrooms" that "erases the distinction between curriculum and instruction, between ends and means" (Clandinin \& Connelly, 1992, p. 392). These ideas act as the foundation for learning in the SPP and lead students to appreciate that learning is a blend of content and context. The program is further grounded in ways of knowing the value of evidence-based knowledge and critical thinking skills that lead to innovative and creative understandings of experiences of health.

The original framework for curriculum was a response to concerns expressed by leaders in healthcare institutions (National League for Nursing, 2003; Canadian Association of Schools of Nursing, 2005) that new graduates are not always ready to work in today's rapidly changing healthcare system. Nursing education that prepares a workforce to practice effectively in changing and technologically sophisticated healthcare environments is essential. Such education needs to enable the student to be self-directed and ready to apply evidence-informed knowledge in practice (Canadian Association of Schools of Nursing, 2005). This concern has been voiced by both academics and practitioners (Eggertson, 2013). Instead of a singular focus on content and clinical skills, as is the case in many nursing programs, the SPP is thematically and competencybased. It is grounded in the competencies that nurses need in order to care for healthcare consumers today and in the future.

The program is also based on Dahlgren and Whitehead's (1991) Determinants of Health model, in which the health system and social determinants of health come together and represent the complexity of the environment where nurses practice. In Figure 1, the original layers of the model are enveloped by a further layer that represents the characteristics of the nurse of the future who engages with clients to co-create health. Figure 1 also presents the dimensions of perspective (promotion, protection, prevention, maintenance, and end of life); context (person, health, environment, and nursing); and process (caring, critical thinking, communication, and change). 
Figure 1

Curriculum Framework as based Dahlgren and Whitehead (1991)

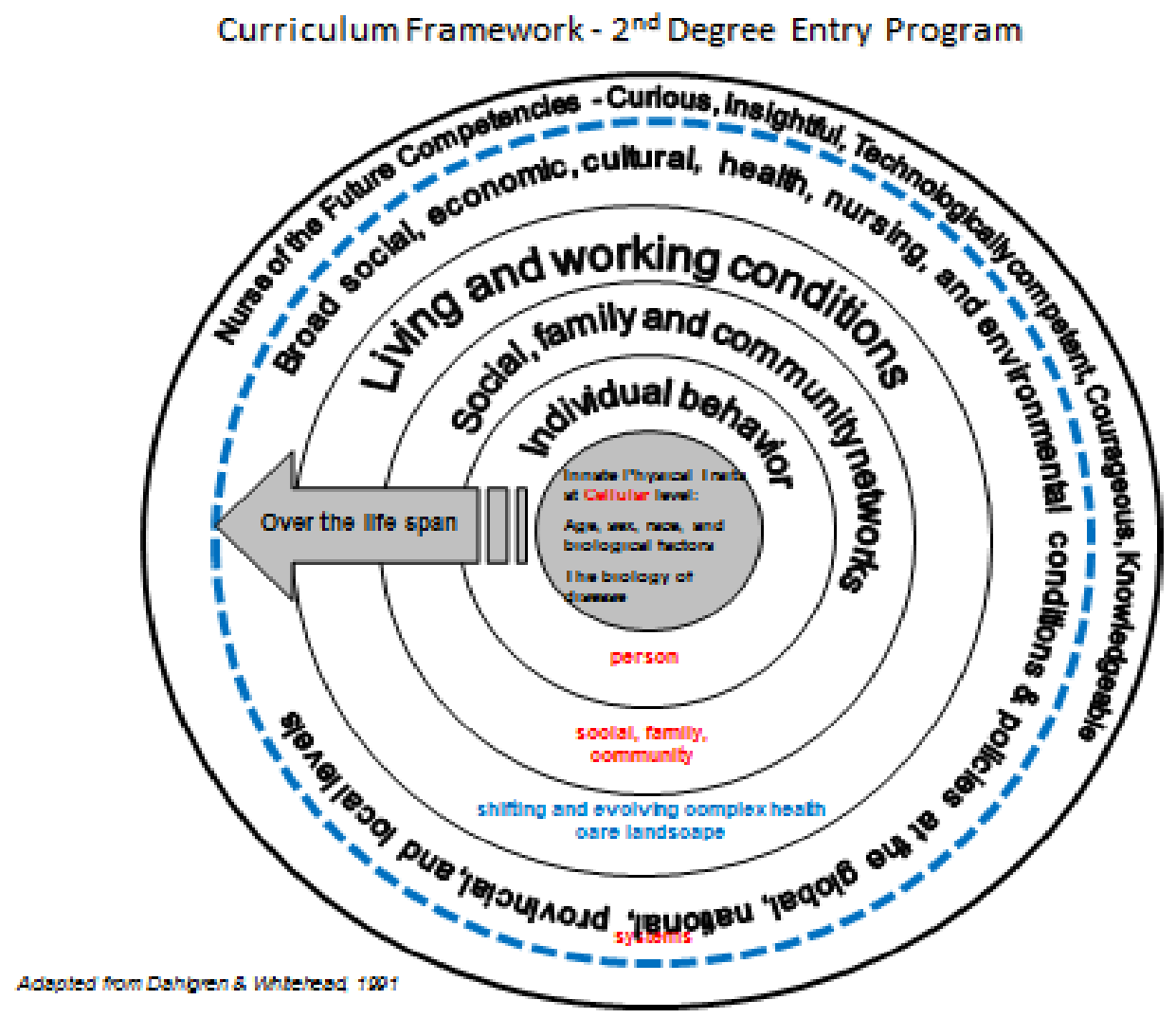

Seminal work by adult learning theorists Schon (1983) and Schwab (1973) have influenced the program. Their work emphasizes multidimensionality and complexity and is situated in the concepts of learner, professor, milieu which includes the preceptor and client; and the subject matter as content. Extrapolating these ideas, the purpose of each learning moment is to add depth, meaning, and relevance to the student's developing practice. Because nursing is a practice profession, learning experiences need to contribute to and enhance role socialization and understanding of professional practice.

Still aligned with Schon (1983) and Schwab (1973), the concepts of learner, professor, milieu, and subject matter comprise the context within which co-learners learn to acquire nursing knowledge. The second dimension derives from the perspectives with which nurses approach their work: health promotion, health protection, health restoration, health maintenance, and endof-life care. The third dimension focuses on the processes that student nurses, as co-learners, use in co-creating health with clients: caring, communication, critical thinking, and change. These philosophical perspectives originally emerged from exploration and adaptation of the curricular framework used in the University's undergraduate nursing program. While similarities exist with this curricular framework, the SPP is contextually and pedagogically distinct from other programs offered by the School of Nursing. 
In summary, the essence of the SPP curriculum emerges through interactions among faculty and co-learners. These interactions take place in scheduled learning sessions, lab settings, and clinical practice settings. The participants within these interactions are co-learners, adjunct professors, faculty from the University, practicing nurse preceptors, members of the health care team, and clients. The curriculum is what occurs within these relationships and comes to life through purposeful explorations of program-relevant content. The roles of professors and learners are fluid and dynamic.

Given the above description of the program, it should be clear that the SPP offers an alternative to other nursing programs that may be more structured and prescriptive. As such, there are persons and organizations that wrestle with the program as a viable form of nursing education. What is sometimes forgotten is that this is a second degree program that serves adult learners who have deliberately chosen nursing after completion of a first degree. As well, the program does align with the principles and practices of adult education and government's current commitment to experientially-oriented university education in order to ensure practice-ready graduates (Ministry of Training Colleges and Universities, 2013).

\section{Teamwork}

The SPP has been successful because of the exceptional teamwork by faculty from the University, the adjunct professors at the urban site, the program manager, and the co-learners. All stakeholders have been engaged in a discovery that this educational initiative, like other experiences of educational innovation, has been characterized by various hurdles. Some of these include the reactions of others-other nurses, academics, professionals, and public memberswhen they try to understand how the program functions. Presenting the program accurately within the requirements of a highly prescriptive accreditation process has presented challenges. While there is will to understand by others, when assessment strategies and accreditation processes are not straightforward fits with the actual program, there is risk of misunderstanding and misinformation. The fact that there is physical distance between the urban campus and the main campus of the university is another complex variable. Extra effort has been required by program administrators to ensure that SPP students are receiving the same supports and services as students on the main campus. Maintaining a rich and robust relationship with the School of Nursing has required creative and sustained effort.

The experiences of those most closely involved in the SPP program are not unlike the angst that e-learning in universities has generated. In the e-learning literature, some scholars argue that technology changes how people learn (Tapscott, 2008) while others suggest that learning is the same as it was in years past-that learning is a situation that involves dedicated time on task and access to expert knowledge (Bullen et al., 2011). What really matters is that people are learning; still, angst continues.

In the SPP, what students are learning is identical to what students in other nursing programs are learning. They are simply using alternate ways of getting to the same destination; this destination involves competence and confidence as nursing graduates who will be successful on their licensing exams and who will demonstrate safety in the care of their patients. How they learn is, in many ways, similar to the principles and strategies found in the early adult education literature (Knowles, 1978). Adults need to know why they need to learn something and to learn experientially whenever possible. They also need to be provided opportunities for critical thinking and evidence-informed decision making (Carter, 2008). In the SPP, knowledge acquisition is evidenced in co-learners' individualized learning plans, reflective journaling 
assignments, scholarly submissions, formal exams, quizzes, and learning portfolios. Taken together, these learning experiences and artefacts demonstrate the wide range, depth, and outcomes of learning journeys targeting achievement of semester-specific objectives. The use of resources and repositories made available through the University and affiliate organizations support additional individualized learning.

\section{Discussion}

\section{Institutional and Partner Learning}

The practice of the adjunct faculty within affiliate academic health care organizations is critical to the program's infrastructure, which must balance scholarly learning with point-of-care experiential practicums. Shared equal risk and investment by the affiliate health care organizations and the University characterize all aspects of program infrastructure. Scheduled Advisory Steering Committee meetings illustrate this engagement. Standing agenda items include administrative, curricular, preceptorship-based, research, and evaluation updates, all of which represent commitment to transparency for all stakeholders. This model of shared governance has been recognized as highly engaging according to formative and summative evaluation indicators (Nipissing University, 2013). Administratively, stakeholders see the seamless transition along the learning trajectory of student, graduate, and new employee as return on their investment. Program graduates demonstrate integration into the culture and environment of the nursing profession within their organizations. Formal and informal communications provide evidence of high regard for professionalism and the benefits of one-toone preceptorship. In other programs, students are placed in clinical units as a group, and, therefore, do not benefit from a continued or consistent preceptor. In other nursing education contexts, due to a lack of appropriate clinical experiences, students must rely on the use of clinical simulation to augment their clinical hours and exposure to certain clinical situations such as pediatrics. To date, this challenge has not presented within the SPP model. In short, integration of concepts by learners, professors, milieus, and preceptors within a pedagogical context of narrative inquiry distinguish the program from other compressed programs offered at the undergraduate level.

\section{Organizational and Operational Levels}

The SPP adjunct faculty who are employees of their respective health care organizations have reported how this program challenges traditional modes of teaching and learning and inspires creativity. This evolution in learning and assessment strategies is carefully embedded within the curriculum. In formative curricular documents, efforts to align unconventional approaches with conventional and traditional paradigms met with frustration. However, while some changes have occurred with time and experience, the narrative aesthetic experience remains at the forefront of both faculty retention and student-preceptor engagement. Keeping cohorts to no more than 50 students is also important to sustaining a sense of community in the program and to the program philosophy itself.

Changing education means changing how one defines educational moments. The activities and measures of traditional pedagogies do not always fit the practice environment nor the opportunities and realities experienced by individual learners. Narrative inquiry in a cognitive apprenticeship model situates learning as stories told by clients, families, teachers, practitioners, and clinical preceptors. These stories are then experienced and interpreted by students within learning groups. Faculty act as guides to interpretation and not as traditional "subject matter experts"; they generate and share other stories and cases situated in various 
paradigms (Swenson \& Sims, 2000). As validated by Lindsay (2006) and Lindsay and Smith (2003), the primary resource of the faculty educator is his or her experience of being a nurse and understanding that nursing education is a mutually enlightening role. This approach aligns with Clandinin's (2006) view that faculty knowledge is exclusive "storied life compositions" reflecting life history and social milieu.

Inclusivity within the program infrastructure and mutual dialogue are evident in the semester meetings between program faculty, administration, and the SPP co-learner council composed of learner representatives from the cohort. This forum is characterized by transparency and an identity as a community of learning in relation to administrative and curricular matters. Each meeting generates discussion of program strengths and opportunities for enhancement of the program and its delivery.

\section{The Philosophy of Becoming a Scholar Practitioner}

Use of narrative inquiry in the program requires an epistemology of occupational knowledge and questioning, "How does one know what one knows? What do nurses know?" These are the questions that build a community identity and a community of practice within nursing; they are questions based on procedural, relational, and vocational knowledge (Benner, 1984; Swenson \& Sims, 2000). Through an integration of classroom and clinical knowledge via narrative inquiry, faculty and students engage-through the telling of stories or alongside others - in living out stories. This action leads to the creation of relationships based on mutual understanding at the point of care setting. Faculty participate in exploration, self-discovery, and professional development based on their experiences of narrative inquiry pedagogy. As they make revisions to curricular documents and strengthen how they present and explain the program to others, they are experiencing personal and professional growth.

To date, program students and graduates have attained executive positions within provincial nursing bodies, sought specialty education in nursing, and enrolled in post-graduate health care programs as part of a lifelong learning philosophy. Leadership is also evident within new graduate point-of-care positions within urban critical care units, district health units, and remote nursing employment posts; each setting offers a valuable opportunity to grow and shape SPP graduates within the nursing profession.

\section{Final Thoughts}

At this point in its evolution, is the program evolving as it was conceptualized? Yes and no. Positively, the program is now 'on the radar' of individuals seeking an alternate form of nursing education after completion of a first post-secondary degree. Extensive curricular work has been completed, and substantive work has been accomplished in relation to program evaluation and revision work. The University is in the process of resourcing the program with tenure track faculty and other infrastructure supports for program participants.

What could not have been envisioned was the extent of the diverse hurdles that the program has experienced. As described in this paper, these challenges have ranged from attitudinal to practical problems, from hiccups in relation to being a remote campus to the considerable work required to meet the requirements of external oversight bodies.

As for next steps, continued education of the public that this kind of nursing education exists in Canada is vital. Education of others in the larger nursing community and within partnering institutions, including the University and healthcare partners in large urban areas, is also important. The former is necessary so that students are able to make choices that fit their 
learning needs while preparing them in strategic ways for work. The latter is required so that the value of this program can be appropriately and effectively articulated by those closest to it when they are engaged in conversations with others who may have questions. It is in one to one conversations and celebrations that acknowledge the successes of students that attitudes and perceptions change. Future research into program outcomes and their longitudinal sustainability is required.

In his famous poem "The Road Not Taken," American poet Robert Frost shares a reflection about a person who takes the road less travelled and how doing so has made all the difference. Such is the case for the SPP. The genesis, development, and delivery of the program are different and, hence, the experiences of stakeholders, from faculty to students, are not the same as those in more traditional programs. What remains the same is that the SPP is graduating skilled nurses who understand the healthcare world as one in which they need to be lifelong learners, strong thinkers, and capable scholars. 


\section{References}

Beckmann, E. A. (2010). Learners on the move: Mobile modalities in development studies. Distance Education, 31(2), 159-173. doi:10.1080/01587919.2010.498081

Benner, P. E. (1984). From novice to expert: Excellence and power in clinical nursing practice. Menlo Park, CA: Addison-Wesley Publishing Company.

Bevis, E. O., \& Watson, J. (1989). Toward a caring curriculum: A new pedagogy for nursing. New York, NY: National League for Nursing.

Brocade. (2011). Enterprise and mobility: What e-living is teaching about e-learning? San Jose, CA: Brocade Communication System. Retrieved from http://www.brocade.com/downloads/documents/technical_briefs/mobility-e-living teaching-e-learning-tb.pdf

Brown, S., Kirkpatrick, M., Mangum, D. \& Avery, J. (2008). A review of narrative pedagogy strategies to transform traditional nursing education. Journal of Nursing Education, 47(6), 283-287. doi:10.3928/01484834-20080601-01

Bullen, M. (2011). Separating fact from fiction in the digital generation discourse. Online presentation to IT. Sligo, Ireland.

Bullen, M., Morgan, T., \& Qayyum, A. (2011). Digital learners in higher education: Generation is not the issue. Canadian Journal of Learning Technology, 37(1).

Canadian Association of Schools of Nursing. (2005). Position statement on baccalaureate education and baccalaureate programs. Ottawa, CA.

Carter, L. (2008). Perceptions of writing confidence, critical thinking, and writing competence among registered nurse-learners studying online. Canadian Journal of University Continuing Education, 34(2), 63-87.

Carter, L., \& Graham, R. (2012). The evolution of online education at a small northern university: Theory and practice. Journal for Distance Education/Revue de l'Éducation à Distance, 26(2).

Carter, L., \& Salyers, V. (2013). E-learning as educational innovation in Canada: Two case studies. In L. Shavinina (Ed.). International handbook of innovation education. New York: Taylor \& Francis/Routledge.

Clandinin, D. J. (2006). Narrative inquiry: A methodology for studying lived experience. Research Studies in Music Education, 27(1), 44-54. doi:10.1177/1321103X060270010301

Clandinin, D. J. (2007). Preface. In D. J. Clandinin (Ed.), Handbook of narrative inquiry: Mapping a methodology. Thousand Oaks, CA: Sage.

Clandinin, D. J., \& Connelly, F. M. (1992). Teacher as curriculum maker. In P. W. Jackson (Ed.), Handbook of research on curriculum. New York: MacMillan Publishing.

Clandinin, D. J., \& Connelly, F. M. (1994). Personal experience methods. In N. K. Denzin and Y. S. Lincoln (Eds.), Handbook of qualitative research (pp. 413-427). Thousand Oaks, CA: Sage.

Connelly, F. M., \& Clandinin, D. J. (1990). Stories of experience and narrative inquiry. Educational Researcher, 19(5), 2-14. doi:10.3102/0013189X019005002

College of Nurses of Ontario. (2013). Nursing Registration Exams Report. Toronto, ON.

College of Nurses of Ontario. (2014). Nursing Registration Exams Report. Toronto, ON.

Dahlgren, G., \& Whitehead, M. (1991). What can be done about inequalities in health? The Lancet, 338(8874), 1059-1063. http://dx.doi.org/10.1016/0140- 6736(91)91911-D 
Eggertson, L. (2013). The gap between clinical practice and education. Canadian Nurse. Retrieved from http://www.canadiannurse.com/en/articles/issues/2013/september2013/the-gap between-clinical-practice-and-education

El-Hussein, M. O., \& Cronje, J.C. (2010). Defining mobile learning in the higher education. Journal of Educational Technology and Society, 13(3), 12-21.

Ellis, A. (2005). Research on educational innovations $\left(4^{\text {th }}\right.$ ed.). Larchmont, NY: Eye on Education.

Higher Education Quality Council of Ontario. (2013, April). Quality: Shifting the focus: A report from the expert panel to assess the strategic mandate agreement submissions. Retrieved from http://www.heqco.ca/SiteCollectionDocuments/FINAL\%20SMA\%20Report.pdf

Knowles, M. (1978). The adult learner: A neglected species. (2nd ed.). Gulf Publishing: Houston, TX.

Lindsay, G. M. (2006). Experiencing nursing education research: Narrative inquiry and interpretive phenomenology. Nurse Researcher; 13(4), 30-47. http://dx.doi.org/10.7748/nr2006.07.13.4.30.c5988

Lindsay, G. M., \& Smith, F. (2003). Narrative inquiry in a nursing practicum. Nursing Inquiry, 10(2), 121-129. doi:10.1046/j.1440-1800.2003.00165.x

Margaryan, A., Littlejohn, A., \& Vojt, G. (2011). Are digital natives a myth or reality? University students' use of digital technologies. Computers \& Education, 56(2), 429-440. doi:10.1016/j.compedu.2010.09.004

Miller, R. (2002). Free schools, free people: Education and democracy after the 1960s. Albany: State University of New York.

Miller, C. D., Finley, J., \& McKinley, D. L. (1990). Learning approaches and motives: Male and female differences and implications for learning assistance programs. Journal of College Student Development, 27, 147-154.

Ministry of Training Colleges and Universities. (2013). Strengthening Ontario's centers of creativity, innovation and learning. Queens Printer for Ontario.

Morse, J. M., \& Richards, L. (2002). Read me first for a user's guide to qualitative methods. Thousand Oaks: Sage.

National League for Nursing. (2003). Innovation in nursing education: A call to reform [Position statement].

Nipissing University. (2013). Second degree BScN scholar practitioner program (SPP) program evaluation report 2013-2014.

Parson, V., Reddy, P., Wood, J., \& Senior, C. (2009). Educating an iPod generation: Undergraduate attitudes, experiences and understanding of vodcast and podcast use. Learning, Media \& Technology, 34(3), 215-228. doi:10.1080/17439880903141497

Reichert, J., Solan, B., Timm, C., \& Kalishman, S. (2008). Narrative medicine and emerging clinical practice. Literature and Medicine, 27(2), 248-271. doi:10.1353/1m.0.0028

Reeves, P., \& Reeves, T. (2008). Design considerations for online learning in health and social work education. Learning in Health and Social Care, 7(1), 46-58. doi:10.1111/j.14736861.2008.00170.x

Ryan, M., Carlton, K., \& Ali, N. (2004). Reflections on the role of faculty in distance learning and changing pedagogies. Nursing Education Perspectives, 25(2), 73-80. http://dx.doi.org/10.1043/1094-2831(2004)025<0073:ROTROF>2.0.CO;2 
Salyers, V., Carter, L., \& Barrett, P. (2010, Nov). Evaluating student and faculty satisfaction with a pedagogical framework. Presentation at the Centennial Symposium on Scholarship of Teaching and Learning Conference. Banff, AB.

Salyers, V., Carter, L., Barrett, P., \& Williams, L. (2010). Evaluating student and faculty with a pedagogical framework. Journal of Distance Education/Revue de l'Éducation à Distance, 24(3). Retrieved from http://www.jofde.ca/index.php/jde/article/view/695/1145

Schon, D. A. (1983). The reflective practitioner: How professionals think in action. New York: Basic Books.

Schwab, J. J. (1973). The practical 3: Translation into curriculum. School Review, 81(4), 501522.

Stalmeijer, R., Dolmans, D., Wolfhagan, I., \& Scherpbier, S. (2009). Cognitive apprenticeship in clinical practice: Can it stimulate learning in the opinion of students? Advancements in Health Science Education, 14(4), 535-546. doi:10.1007/s10459-008-9136-0

Swenson, M. M., \& Sims, S. L. (2000). Toward a narrative centered curriculum for nurse practitioners. Journal of Nursing Education, 39(3), 109. doi:10.3928/0148-483420000301-05

Tapscott, D. (2008). Grown up digital: How the net generation is changing your world. McGraw-Hill. 